\title{
ORALIDAD Y NARRACIÓN. UN ESTUDIO DE CASO
}

\author{
Esther Morillas \\ emorillas@uma.es \\ Universidad de Málaga
}

\section{Resumen}

El recurso a la oralidad como estrategia discursiva en textos escritos no es en absoluto nuevo, pero se podría decir que es uno de los que más se potencian en la producción literaria contemporánea. A través del análisis de la novela La briscola in cinque de Marco Malvaldi y de su traducción al castellano, La brisca de cinco, a cargo de Juan Carlos Gentile Vitale, se pretende ilustrar el proceso por el que los elementos que distinguen (al menos convencionalmente) a la oralidad se trasvasan de una lengua a otra. Se prestará especial atención al dialogismo, a su expresividad, al papel que el dialecto desempeña dentro de este y a su interrelación con el humor.

\begin{abstract}
"Narrative and orality. A case study"

Orality used as a discursive strategy in written texts is nothing new. However, it could be said to be one of the most promoted strategies in contemporary literary production. Through the analysis of Marco Malvaldi's novel La briscola in cinque and its translation into Spanish, by Juan Carlos Gentile Vitale, I will illustrate the process through which the elements that characterize orality (at least, conventionally) are translated from one language to another. Dialogism will be especially relevant to this study, as well as its expressivity, the role of dialect and its relationship with humor.
\end{abstract}

Palabras clave: Traducción literaria. Dialecto. Dialogismo. Humor. Marco Malvaldi.

Keywords: Literary Translation. Dialect. Dialogism. Humor. Marco Malvaldi.

Manuscript received on April 13, 2015 and accepted for publication on September $18,2015$. 



\section{Introducción}

Marco Malvaldi, por aquel entonces investigador en Química de la Universidad de Pisa, alcanzó un éxito instantáneo con la primera novela que publicó, La briscola in cinque (2007), éxito que ha ido aumentando con sus sucesivas obras. La briscola in cinque abre la (hasta el momento) pentalogía del BarLume ${ }^{1}$, y es precisamente en este bar de un imaginario pueblo de la Toscana, Pineta, donde transcurre la mayor parte de la acción ${ }^{2}$. Se trata de una serie de novelas policiacas, cuyos conflictos serán resueltos por Massimo, dueño y camarero del local, y los parroquianos más aguerridos: cuatro ancianos (entre los que se encuentra el abuelo del propio Massimo) que charlarán, despotricarán, discutirán, jugarán a las cartas y contribuirán a desentrañar enigmas criminales utilizando un lenguaje informal y colorista.

La crítica italiana coincide en señalar que, más que la historia en sí, o mejor dicho, además de la historia, lo que caracteriza a esta pentalogía es el modo en que se utiliza el lenguaje, cómo se cuenta la historia. Si por algo se distinguen estas novelas es por su inmediatez comunicativa, por el puente constante que hay tendido entre narrador, personajes y público lector. En este sentido, me parece muy pertinente la observación que realiza Goetsch (1985: 218, apud Brumme 2012: 16) acerca "de que la 'oralidad fingida' forma parte de la función apelativa propia de los textos ficcionales y se integra, junto con otras estrategias, en los recursos retóricos generales de estos." Tal función apelativa será la que, en definitiva, regirá las estrategias que se adopten a la hora de traducir la oralidad y así, teniendo siempre presente que el dialogismo es el elemento principal de La briscola in cinque (junto a la ironía, encarnada

1. Le siguen Il gioco delle tre carte (2008), Il re dei giochi (2010), La carta più alta (2012) e Il telefono senza fili (2014), todas ellas publicadas en Sellerio. Se han traducido al español La brisca de cinco y El juego de las tres cartas, ambas publicadas en la editorial Destino en 2012, luego reeditadas en una trilogía junto a El rey de los juegos en Círculo de Lectores en 2013, todas ellas traducidas por Juan Carlos Gentile Vitale.

2. Juan Carlos Gentile Vitale explica en nota el juego de palabras que encierra el nombre del bar: "Bar Lume significa 'destello, vislumbre', por lo que el nombre del establecimiento, así escrito, puede entenderse de dos formas: Bar Luz y Destello." (Malvaldi 2012: 18) 
en el protagonista principal, Massimo, pero también en los abuelillos con retranca) me será muy fácil entonces reflexionar sobre la traducción de la oralidad partiendo de esta novela, de la que iré tomando ejemplos para tratar a lo largo del presente trabajo distintos aspectos.

\section{El habla escrita}

Como es bien sabido, la oralidad se ofrece esquiva al texto escrito, y especialmente al literario, que no alcanza a imitarla fidelísimamente (estaríamos, en caso contrario, ante una transcripción, no ante una recreación). La escritura sirve para filtrar muchos de los fenómenos que caracterizan al habla (anacolutos, comienzos en falso, interrupciones), de modo que la lectura se agilice. Son muchas las denominaciones que se han ofrecido para esta plasmación de lo oral en lo escrito, comenzando por el parlato-scritto de Nencioni (1983: 175) o el concepto de "oralidad ficcional" que defiende Brumme (2012: 33) y que entiende como "la evocación del lenguaje de la inmediatez comunicativa en los textos ficcionales, ya sean textos literarios o textos audiovisuales, distinguiéndola de la oralidad cotidiana o real." También es muy utilizada la definición de "mímesis de la oralidad" propuesta por Narbona Jiménez (2001) o López Serena (2007), o la de "oralidad prefabricada" de Chaume (2004: 168) aplicada a la traducción audiovisual. Desde mi punto de vista, adjetivos como "simulada", "prefabricada", e incluso "ficcional", aun siendo muy reveladores no dejan de tener unas connotaciones de artificiosidad que no terminan de convencerme: es como si la propia definición asumiera la imposibilidad de trasladar la oralidad al texto impreso y, por más que yo misma haya comenzado el presente apartado señalando dicha imposibilidad, como advertía Genette (1966: 156) toda imitación es imperfecta, porque si no lo fuera no se trataría ya de una imitación. En este sentido, el maravilloso oxímoron utilizado por Nencioni de "habla escrita" me resulta el más sintético y carente de (pre)juicios.

Partamos de la base de que en el propio acto de leer ya hay una serie de procesos mentales que contribuyen al disfrute (en las varias acepciones de la palabra) de una obra escrita. La entonación, quiero recordarlo ahora, es un elemento inherente a la oralidad. Pero cuando leemos, aunque sea sin emitir sonido alguno, entonamos también: nos ayudan a ello los signos de puntuación, la sintaxis, las posibles indicaciones que va proporcionando la persona que escribió el texto. Como sabemos quienes nos dedicamos a la enseñanza de lenguas, la entonación es un signo de comprensión: los errores de énfasis son errores cognitivos. La función entonces del elemento dialogizante en una novela es que "oigamos" las diversas voces que hablan (esa función 
apelativa a la que antes aludía con Goetsch: "eh, escuchad a mis personajes, están hablando"): a mayor pericia del narrador o de la narradora, mayor verosimilitud, mayor pluralidad vocal. Y que la oralidad, la oralidad escrita, es perceptible y analizable, parece indiscutible, y estaremos de acuerdo en la existencia de rasgos que nos permiten reconocer a un texto escrito como "oral", empezando por la inserción del diálogo, o el monólogo, marcados o no tipográficamente, o la utilización de recursos como la parataxis, determinados conectores, interjecciones, etc., además del repertorio léxico elegido. Como bien afirma Narbona Jiménez (2009: 116),

[a] la literatura, por basarse en la ficción, le es posible fingir también todas las modalidades de uso de la lengua, incluidas las pertenecientes a la oralidad prototípicamente coloquial. [...] Tal experimento o experiencia literaria, de alto riesgo y no al alcance de cualquiera, requiere contar con cómplices y avezados lectores, capaces de enfrentarse a tipos de textos y de géneros discursivos cada vez más diversificados.

Si quien traduce, como se ha repetido tantas veces, es un lector privilegiado o una lectora privilegiada, entonces podrá asumir sin más ese "experimento", sirviéndose de los recursos que su lengua le proporcione y dentro también de una serie de convenciones.

Pero ¿por qué traducir la oralidad parece suscitar una serie de problemas que no plantea el lenguaje estándar? La necesidad expresiva de la literatura llevó a esta a buscar fórmulas para ser todo lo más verosímil posible en la caracterización de lugares, hechos y personajes, y dicha verosimilitud pasaba, en lo que respecta a la lengua italiana, por abandonar la lengua convencionalmente (subrayo esa palabra) literaria en pro de lo que Coletti (1993: 357-363) ha llamado el "trionfo dell'italiano medio". Aunque el abandono de lo convencionalmente literario sea un elemento recursivo de la tradición literaria (la literatura se renueva superando periódicamente lo que es hasta entonces convencionalmente literario), digamos que encontrarnos hoy con el habla escrita no debiera sorprendernos: la aproximación a lo hablado pertenece a la convención literaria vigente. E incluso ya contamos con una tradición (aunque en algunos casos por ausencia) en lo que a la traducción de esa modalidad expresiva se refiere, de forma que la norma actual exige que el habla escrita se traduzca como tal, y no como lenguaje estándar, por más que determinados aspectos (luego hablaremos de ellos) se presenten como intransferibles.

Así pues, la oralidad traducida es una realidad ${ }^{3}$, realidad que influye además sobre la nueva oralidad escrita, en un flujo de interferencias. Antonelli (2006: 8) explica cómo los autores jóvenes italianos no cuentan entre sus

3. Y no solo en lo que respecta a la literatura: cfr. San Vicente $\&$ Morillas (2014). 
fuentes de inspiración con la tradición literaria de su país, sino que los inspiran el cine y la televisión o, en todo caso, la narrativa angloamericana que leen traducida. La traducción así se convierte en una vía de exploración y contaminación literaria, y está claro que en la literatura italiana, en el caso de los diálogos, la influencia del neorrealismo, con su experimentación a través del uso del dialecto y de un lenguaje que reflejara el que realmente debieran hablar los propios personajes, fue decisiva, como lo fue la asimilación de autores estadounidenses a través de la labor editorial capitaneada por Vittorini (Turi 2011).

Brumme (2012: 47-48) hace referencia a algunos trabajos que documentan el cambio lingüístico a través de la traducción y recuerda por ejemplo el caso emblemático de The Catcher in the Rye, cuya traducción al alemán supuso una renovación del sistema literario, de igual modo que lo supuso también en la lengua italiana, que tuvo que ampliar su registro para dar cabida a la voz de Holden (Morillas 2008). Paulatinamente, pues, se han ido incorporando y haciéndose comunes las marcas orales en las traducciones. Como la misma Brumme (2012: 229) apunta en las conclusiones a su volumen, hay que saber distinguir

entre los recursos que son novedosos y, por tanto, transgreden las normas convenidas en la cultura de partida, y aquellos que son en mayor o menor medida convencionales. [...] En este sentido, se entiende que una primera traducción de una obra innovadora pueda requerir, tras haberse aceptado en la cultura meta las innovaciones, una nueva versión más audaz que la que se presentó en un momento inicial. No hay que olvidar que el entramado entre las condiciones de creación y recepción se ajusta a las condiciones socioculturales en cada época y el propio lenguaje literario experimenta transformaciones a lo largo del tiempo. Así pues, algunos de los recursos, si bien novedosos en un principio, pueden llegar a generalizarse.

Podríamos decir entonces que hoy, aunque estemos traduciendo por primera vez obras que hacen uso de formas coloquiales, no estamos traduciendo por primera vez el lenguaje coloquial.

\section{Cuestión de sintaxis}

Resumiendo escuetísimamente, entonces, conversacionalidad y humor son las características que definen La briscola in cinque (insisto, también el resto de la pentalogía). Como ya he apuntado, el tono de la novela es básicamente coloquial-informal. Este deseo de coloquialidad se manifiesta en La briscola in cinque de varias maneras, que iremos viendo, y ya el principio de la obra es casi una manifestación de intenciones:

(1a) Cuando empiezas a tambalearte sobre las piernas; cuando te enciendes otro cigarrillo para que pasen otros cinco minutos (aunque la garganta 
te arda y tengas la boca tan pastosa que parece que te hayas comido un neumático) y que así también los demás se enciendan uno y os quedéis ahí todavía un rato; en fin, cuando todo eso ocurre, ha llegado verdaderamente la hora de irse a la cama.

Eran las cuatro y diez de la mañana en pleno agosto y tres chicos estaban de pie junto a un Micra verde. Habían bebido más de lo estrictamente necesario; el propietario del Micra, más que los otros, que trataban de convencerlo de que no condujera $(11)^{4}$.

No necesitamos de ningún tipo de indicador explícito para darnos cuenta de que la voz a la que pertenece el primer párrafo es distinta a la que habla en el segundo (o, por lo menos, así lo interpreto yo). En el primer párrafo tenemos una larga frase que expresa los pensamientos de uno de los chicos que están a punto de irse a su casa y que están reuniendo valor antes de dar el paso. A través de este monólogo interior (hay bastantes a lo largo de la novela, y más adelante veremos otro en el ejemplo 6) se establece una relación de empatía con los hechos que se narran, pues quien lee tiene la posibilidad de conocer de primera mano los pensamientos del protagonista, de sintonizar con ellos. La afirmación contenida en la frase, que casi podríamos elevar a axioma a través del presente utilizado, se diría que gnómico, se cimenta en un tú que es a la vez dialógico e impersonal y que por tanto implica a los destinatarios y las destinatarias del texto que casi sienten, efectivamente, que las piernas le flaquean, como si formaran parte del grupo que protagoniza la acción.

En el segundo párrafo, nos confirma que los muchachos están un poco bebidos una nueva voz, la de un narrador (vamos a pensar que es un narrador hombre, que podríamos identificar con el autor de la novela) omnisciente, que con la inclusión de ese "más de lo estrictamente necesario" abandona una descripción aséptica para dotar a la narración de subjetividad (uno de los rasgos inherentes al dialogismo) y establecer con los lectores y las lectoras una relación de complicidad y camaradería. Porque no solo en el diálogo propiamente dicho encontramos dialogicidad, sino que también la encontramos en parlamentos como el que acabamos de ver, que manifiestan una voluntad de establecer un contacto más directo, de acortar la distancia que separa a quien escribe de quien lee.

Otros rasgos de dialogismo, o de conversacionalidad, si queremos, contribuyen a dar tono coloquial al texto (hago alusión solo a algunos): la presencia de anáforas, de repeticiones, y de oraciones yuxtapuestas y coordinadas. Encontramos además, en el primer párrafo, un enunciado parentético, una concesiva que incluye una comparación por exageración, típica también del lenguaje dialogado. Aporta un elemento más a la descripción de la situación y acerca la narración al terreno de la intersubjetividad.

4. El número entre paréntesis indica la página de la obra citada. 
De esta forma, al comenzar La briscola in cinque tenemos ante nosotros desde estas primeras líneas el tono de la novela (porque ese será el que se mantenga a lo largo de la obra), el diapasón que va a marcar la relación entre personajes, narrador omnisciente y público lector. Si en las películas de miedo la banda sonora desempeña un importantísimo papel a la hora de mantener la tensión del visionado, en el texto que nos ocupa las estrategias verbales, próximas a un ideal de oralidad, que Malvaldi utiliza buscan dejar claro: a) que la relación que se quiere establecer con quien lee es una relación informal, cordial, y b) que el humor estará presente a lo largo de la obra, reforzando dicha informalidad. O por decirlo de otra forma: lo que Malvaldi nos está proponiendo es una lectura ligera de una obra ligera.

Pero lo que hemos visto ha sido, en realidad, el comienzo de La brisca de cinco, no el de La briscola in cinque, que veremos a continuación, esta vez enfrentado el texto original con su traducción (que, recuerdo, es a cargo de Juan Carlos Gentile Vitale), para que podamos ver qué tipo de correspondencia se establece entre ambos textos. He querido empezar citando la traducción porque en circunstancias normales será la elegida por un lector o una lectora que no lee en italiano, y la idea de la escritura de Malvaldi que tendrá será la que la traducción le sugiera.

El tono marcado por el autor también determinará, evidentemente (o al menos así debiera ser), las tácticas de traducción empleadas, que en este caso deberán ajustarse al deseo de coloquialidad que parece inherente a la narración o que, como acabamos de ver, por lo menos está presente en la traducción.

(1b) Quando cominci a ciondolarti sulle gambe, quando ti accendi un'altra sigaretta per far passare altri cinque minuti anche se hai la gola che ti brucia e la bocca talmente impastata da credere di aver mangiato un copertone, così anche gli altri se ne accendono una e si sta lì ancora un po', insomma quando è così è veramente ora di andare a letto.

Erano le quattro e dieci di mattina, in pieno agosto, e tre ragazzi stavano in piedi accanto a una Micra verde. Avevano bevuto più dello stretto necessario, il propietario della Micra più degli altri. Altri che ora stavano cercando di convincerlo a non guidare. (13)
Cuando empiezas a tambalearte sobre las piernas; cuando te enciendes otro cigarrillo para que pasen otros cinco minutos (aunque la garganta te arda y tengas la boca tan pastosa que parece que te hayas comido un neumático) y que así también los demás se enciendan uno y os quedéis ahí todavía un rato; en fin, cuando todo eso ocurre, ha llegado verdaderamente la hora de irse a la cama.

Eran las cuatro y diez de la mañana en pleno agosto y tres chicos estaban de pie junto a un Micra verde. Habían bebido más de lo estrictamente necesario; el propietario del Micra, más que los otros, que trataban de convencerlo de que no condujera. $(11)^{5}$ 
Como bien insiste Narbona Jiménez (2001: 195) "[e]stá claro que el grado de coloquialidad que se alcance depende fundamentalmente de los esquemas sintácticos empleados." Es quizá lo primero que llama la atención de este fragmento, en el que es la sintaxis el elemento más definitorio, y no tanto el léxico empleado, como ocurrirá en otras partes de la novela. Fijémonos, por ejemplo, en cómo los signos de puntuación cambian del TO al TM, o en cómo marcadores discursivos típicos de la lengua coloquial como insomma (Flores Acuña 2003) se traducen. Pero los cambios producidos en la puntuación, la cual, como ya ha quedado dicho, sirve para ayudarnos a encontrar la entonación adecuada cuando leemos, puede que cambien ligeramente el ritmo de la narración (más acelerado en español, desde mi punto de vista, mientras que el texto en italiano reproduce mejor la lentitud típica del entorpecimiento etílico), pero no el tono de la narración. O dicho de otro modo, y es la reflexión que quería hacer con este primer ejemplo, lo que hay que traducir no son estructuras, ni elementos aislados, lo que hay que traducir es un clima, un ambiente verbal, si se me permite la expresión. ${ }^{5}$

\section{Cuestión de expresividad}

El escritor que introduce la dialogicidad, con sus posibles desviaciones de la norma, y la utiliza como utillaje literario, integrante decorativo o creador de atmósfera, y, las más de las veces, como rasgo caracterizador de sus personajes, lo que hace es evocar, o si preferimos, recrear una atmósfera y una situación comunicativa que, en el curso de la lectura, familiarizará a los lectores y a las lectoras con los lugares y los habitantes del universo narrativo. Al mismo tiempo, y cuando la idiosincrasia de un determinado personaje sea única, se producirá un periodo de extrañamiento, puesto que el público lector tendrá que hacerse con los modos expresivos de dicho personaje, con su idiolecto, hasta poderlo identificar (y en esa identificación de modo de habla y personaje radica el éxito, por ejemplo, de Camilleri y su saga Montalbano, y del propio Malvaldi y su pentalogía del BarLume). Lo que más les resulte extraño de entrada a los destinatarios y las destinatarias de la obra es precisamente, y paradójicamente, lo que más servirá para aproximarlos a su mundo de ficción. Cabría hablar, en estos casos, de un extrañamiento familiarizador.

5. El número entre paréntesis indica la página de la obra citada. 
(2) - E il caffè?

- No me l'ha fatto.

- Non te l'ha fatto? E perché?

- Dice che è troppo caldo.

- Ma saranno cazzi mia se è troppo caldo o no per bere il caffè? Già che c'è quel cauterio della mi' figlia a contammi le sigarette, ora anche il barrista ci si mette a preoccupassi della mi' salute? Ora mi sente!!

Ampelio Viviani, anni 82, ferroviere in pensione, discreto ex ciclista dilettante e incontestato trionfatore della gara di moccoli introdotta (ufficiosamente) all'interno della festa dell'Unità di Navacchio per ventisei anni consecutivi dal 1956, si alza fieramente con l'ausilio del bastone e si dirige garibaldino verso il bar.

- Guardalì com'è partito stavolta, sembra Ronaldo! (21)
- ¿Y el café?

- No me lo ha puesto. qué?

- ¿No te lo ha puesto? ¿Por calor.

- Dice que hace demasiado

- ¡Es problema mío si hace demasiado calor para tomar un café! ¡Ya tengo bastante con la pelmaza de mi hija contándome los cigarrillos, ahora también el camarero se preocupa por mi salud! ¡Me va a oír!

Ampelio Viviani, ochenta y dos años, ferroviario jubilado, discreto ex ciclista aficionado e indiscutible triunfador del concurso de palabrotas (extraoficial) de la fiesta de L'Unità* del municipio de Navacchio durante veintiséis años consecutivos, desde 1956, se levanta furiosamente con auxilio del bastón y se encamina, garibaldino, hacia el bar.

- ¡Mira cómo ha acelerado esta vez, parece Ronaldo!

- ¿Por cómo sostiene el garrote? (19)

*Nombre con el que se conoce a los festivales organizados periódicamente en numerosos municipios de Italia primero por el Partido Comunista Italiano, después por el Partido Democrático de la Izquierda y finalmente por los Demócratas de Izquierdas y que debe su nombre al periódico L'Unità. (N. del T.)

Esta es la presentación de Ampelio, el abuelo de Massimo: y Massimo, su nieto, no quiere servirle un café, no porque le vaya a sentar mal a su abuelo, sino porque hace demasiado calor como para ponerse a hacerlo. Ampelio es el ganador, durante veintiséis años consecutivos, del concurso de palabrotas de Navacchio. Es un dato que hay que tener en cuenta. Estamos, no obstante, a principios de la novela, y todavía no hemos visto a Ampelio en todo su esplendor. Quizá por ese motivo la traducción ofrecida de Ma saranno cazzi mia (con 
ese mia dialectal; hablaremos del dialecto en seguida) sea 'Es problema mío'. Y aquí entramos de lleno en la expresividad y sus diferentes manifestaciones, que constituyen la esencia de la oralidad y, por tanto, de su traducción.

Si ya ha quedado demostrado con diferentes análisis (Rojo López \& Valenzuela Manzanares 2000; Soler Pardo 2013) que a la hora de traducir fucking no existe una correspondencia estadística entre TO y TM, y ello, entre otros motivos, porque fucking funciona muchas veces como mero intensificador antepuesto a un sustantivo, lo mismo puede decirse de la italianísima expresión cazzi miei, traducible la mayoría de las veces como 'asunto mío', 'problema mío'. La cristalización de este tipo de expresiones, muy utilizadas en el lenguaje cotidiano, disminuye la percepción por parte de quien la utilice o la oiga del término malsonante, a la vez que determina su traducción que, aunque rebaje el nivel expresivo, sí que suele corresponderse (pongo énfasis en el suele) con la frecuencia de uso de una y otra fórmula en uno y otro idioma. Dicho de manera distinta: traducir saranno i cazzi mia por 'es problema mío' supone una traducción adecuada tanto desde el punto de vista semántico como desde el punto de vista pragmático. En ambos casos el mensaje subyacente es "ocúpate de tus asuntos y déjame a mí en paz". Ahora bien, teniendo en cuenta el dato aportado en la descripción del personaje, en este caso quizá hubiera sido conveniente añadir un poco de énfasis a la traducción, ofreciendo como solución algo semejante a 'Qué coño le importará a él'. Se realizaría un cambio de sujeto, sí, pero se haría hincapié en el uso del término malsonante, redundando a favor del prestigio palabrotero, si se me permite el neologismo, de Ampelio, uno de sus rasgos caracterológicos.

El uso del dialecto como catalizador y filtro del lenguaje malsonante es muy común. El dialecto, entre otras cosas, sirve para atenuar la carga disfémica de determinados enunciados: posee una función eufemística. Por supuesto que en La briscola in cinque no solo encontramos tacos en dialecto (en este caso el vernáculo livornés), pero dado que este es expresión del lenguaje hablado, coloquial, no es extraño que en los parlamentos que se sirven de él, o que lo mezclan con el italiano, nos lo encontremos. El mismo Malvaldi explica en una entrevista (Paloscia en línea) por qué lo usa:

Io, invece, faccio parlare in vernacolo solo i personaggi provenienti da quello strato sociale che non può esprimersi altrimenti, ovvero tre dei quattro detective anziani: Ampelio pensionato delle ferrovie, Del Tacca ex impiegato comunale, Rimediotti. Aldo no: è un intellettuale, parla un italiano forbito e vetusto.

Como bien subraya Ricci (2013: 88), es habitual que la novela negra, por su voluntad de ofrecerse como crónica paródica o fidedigna de lo real, abunden 
rasgos sintácticos y lexicales que pretenden recrear la coloquialidad. Como consecuencia, los diálogos se permean de frases en dialecto que marcan situaciones típicas del género o que, como explica el propio Malvaldi, determinan el estrato social al que pertenece un personaje. Aunque las perspectivas del dialecto experimenten un proceso de ajuste, la identificación dialecto-estrato social se perpetúa en las obras de ficción, aún vigente la tendencia generalizada a traducir los rasgos dialectales por rasgos diastráticos.

Ricci (2013: 84), además, y apoyándose en diversos estudios, destaca cómo en los gialli hay una presencia de dialectalidad mayor que en otro tipo de novela de consumo. Pese a que no siempre la representación de los dialectos sea perfecta, sigue explicándonos, "il bilinguismo italiano-dialetto, con quest'ultimo impiegato come macchia di colore a vivacizzare i dialoghi, è quasi la norma."

En la traducción de La brisca de cinco no encontramos rastro del uso de dialecto, tendencia casi mayoritaria en las traducciones de las últimas décadas (Brumme 2012: 44), aunque sí quedan las marcas de oralidad. La denominación de Massimo como barrista, es decir, el que trabaja en un barre ('bar' en vernáculo), se pierde inevitablemente (aunque un "barrista", en castellano, podría ser aquel que trabaja detrás de la barra). En cuanto, como ya he dicho, el dialecto forma parte del dialogismo, además de servir para caracterizar a los personajes asume una función expresiva y sentimental que no hay que desatender.

Rosa (2015: 5) se vale del parámetro "prestigio" dentro del eje diastrático de la lengua para identificar las distintas estrategias que se siguen a la hora de traducir la oralidad. La normalización (o estandarización), la centralización (se pasa a un discurso más prestigioso, pero no normalizado) y la descentralización (cuando se traduce a un discurso menos prestigioso) son las tres estrategias que individualiza (Rosa 2015: 6). De esta forma, subraya, puede ser que nos encontremos en la traducción con una situación comunicativa diversa, y ante una variación en el grado de prestigio de la lengua empleada. En el caso de La brisca de cinco y de la (no) traducción del dialecto no podría hablarse estrictamente de normalización, puesto que al pertenecer el dialecto a un contexto de habla informal deberíamos referirnos a un proceso de centralización: seguimos en la esfera de lo coloquial, pero abandonando el dialecto y sus implicaciones. Para la tercera opción, la opción de descentralización, tendríamos como ejemplo la traducción de la palabra bastone, para la cual se ofrecen dos equivalencias en el ejemplo 1, 'bastón' y 'garrote'. La segunda opción remite inmediatamente a un contexto rural, con su concatenación de imágenes pueblo-anciano-rusticidad. 


\section{Cuestión de enciclopedia sentimental}

Pero hay otros rasgos en este ejemplo relacionados con la oralidad (dejo ahora de lado deliberadamente cuestiones como las repeticiones, las inversiones sintácticas, etc.) que también están relacionados con la expresión de los sentimientos, rasgos presentes tanto en la parte dialogada como en la puramente descriptiva que, junto con la subjetividad y la afectividad, insisto, involucran a quien lee.

Junto a términos malsonantes, típicos de la conversación distendida, y del uso del dialecto, encontramos referencias a una experiencia común, compartida, sobre la que se cimenta la enciclopedia sentimental de los protagonistas (el adjetivo garibaldino, las fiestas de l'Unità, Ronaldo). Esta experiencia compartida, que es la que permite la comunicación entre personas, o en este caso entre personajes, es igual o incluso más difícil de trasladar que el dialecto (que parece merecer, insisto, "bula" para no ser traducido) cuando se considera que el nuevo público destinatario del texto no comparte ni participa de dicha enciclopedia sentimental. Por eso el traductor de Mavaldi añade a pie de página una nota en la que señala en qué consisten las fiestas de l'Unità. Creo (y quien haya tenido que explicar aspectos culturales en una nota al pie concordará conmigo) que ilustrar en qué consisten las fiestas de l'Unità, sus implicaciones políticas, históricas, folklóricas, culinarias y un largo etcétera, es difícil en pocas palabras. De ahí que el traductor haya optado por describirlas asépticamente desde un punto de vista histórico, más que sentimental, para no formar parte, también él, del diálogo (pues desde las notas también se interviene en el desarrollo de la narración).

No ha necesitado explicación la referencia a Ronaldo, como tampoco el adjetivo garibaldino, con sus connotaciones de audacia, impulsividad y rebeldía que registran los diccionarios italianos, connotaciones fácilmente inteligibles para un lector o lectora de lengua española pero que el DRAE, por ejemplo, no recoge (el lema "garibaldino", directamente, no aparece, sí "garibaldina").

Los elementos culturales no son, evidentemente, exclusivos de la oralidad. Pero todos hemos formado alguna vez parte de una conversación en la que se hablaba de algo o se nombraba a alguien a quien no conocíamos y nos hemos sentido desplazados. En este sentido, la labor del traductor de La brisca de cinco ha sido procurar que ningún lector, que ninguna lectora, se quede fuera de la conversación. Pero cuando hay que explicar demasiados elementos es fácil que se pierda interés por lo que se narra, porque la conversación se interrumpe, de ahí que los escritores y las escritoras conscientes de que el mundo es a la vez grande y pequeño traten de dosificar los elementos 
demasiado idiosincráticos, y los traductores y las traductoras se preocupen de no introducir demasiadas notas a pie, aunque ningún editor o ninguna editora (ignoro si aquí es el caso) les haya dicho nada al respecto. Puede que este sea el motivo por el que Juan Carlos Gentile Vitale añade una amplificatio en ciertas ocasiones (véase, a continuación, el ejemplo 3, entre otros) o sustituye una referencia por otra, en vez de poner una nota a pie de página (ejemplo 4), de modo que la lectura no sufra interrupciones indeseadas:

(3) Somigliava vagamente a Guccini, a proprio agio su quel piazzale come Fvancesco [sic] sul palco. (34-35)

(4) Massimo rientrò al bar e fu accolto da una festosa ovazione dei vecchietti. -Alla grazia di Derrick! (118)
Tenía un vago parecido al cantante Francesco Guccini, y estaba tan en su salsa en aquella explanada como Guccini en el escenario. (34-35)

Massimo regresó al bar, donde fue acogido por una festiva ovación de los viejecitos.

-iA la salud de Sherlock!

La fórmula de saludo alla grazia di es típica de la Toscana y muestra la alegría con la que los abuelos reciben a Massimo, al que comparan con Derrick, el protagonista de una serie detectivesca alemana de televisión que tuvo bastante éxito en Italia. La sustitución de Derrick por Sherlock agiliza la narración y, puesto que no se trata de un elemento cultural "autóctono", la conmutación se justifica en la voluntad de vivacidad discursiva que buscan tanto autor como traductor. En el ejemplo 3 se añade el dato de que Guccini es un cantante, además de proporcionar su nombre de pila, de forma que si el nuevo público destinatario de la novela no lo conoce pueda disponer de los suficientes datos como para buscar qué tipo de música hace o qué apariencia física tiene.

En el ejemplo 5, sin embargo, la sustitución es diversa. Malvaldi (o el narrador de su obra) denomina senato a los abuelos. Si la representación visual que este término tiene en italiano es inmediata, no sucede -creo- lo mismo en español, pues quizá la imagen que se nos venga a la cabeza sea más la de la cámara del Senado, y no la de un grupo de venerandos meditando sobre un tema. En la versión al español leemos 'Imserso' (traducción que, no lo niego, me crea cierta perplejidad). Podríamos entender este cambio como un recurso humorístico que busca la inmediata comprensión por parte de quien lee a través, precisamente, del extrañamiento familiarizador (iexiste también en Italia un Imserso?) o de la representación visual de los grupos de jubilados. Veamos una de las recurrencias: 
(5) Il senato, fuori all'ombra del tiglio grande, stava giocando a canasta e quindi non faceva casino come al solito, una volta tanto. (120)
Fuera, a la sombra del tilo grande, el Imserso jugaba a la canasta, por lo que, por una vez, no armaba follón como de costumbre. (126)

\section{Cuestión de carácter}

He hecho ya alusión a la convencionalidad en la que está inserta la representación de la oralidad, en el sentido de que hay una serie de mecanismos lingüísticos que nos hacen ver que estamos ante un texto de unas características y no de otras, como en el ejemplo 1, en el que estaba claro que se pretendía representar lo coloquial. Es lo que Freunek (2007: 28-30, apud Brumme 2012: 29-30) llama "evocación", y es lo que nos permite reconocer la oralidad cuando se presenta escrita. Cadera (2011: 42) también había tomado prestado este concepto, que explica así:

la evocación se refiere al efecto que surge por el potencial interpretativo del lector de los recursos de la oralidad fingida. De la integración e implicación de estos recursos en el discurso literario depende si el lenguaje convence al lector y por lo tanto evoque aspectos de la oralidad.

De igual manera que hay una convención en esta evocación de la oralidad también hay convenciones en la traducción del hablado escrito. Es, por ejemplo, lo que hoy permite traducir fucking por 'puto' o 'jodido', una desviación de la norma pragmática, por decirlo de algún modo, que se ha convertido ya en norma (Rodríguez Medina 2005: 271), o lo que permite encontrarnos en las traducciones con interjecciones como "idiablos!":

(6) Boia de'. Non si respira dal caldo. Te guarda per questo affettaminchia del Fusco mi vado a chiappare la madre di tutte le insolazioni, accidenti alla sua di madre, quel tegamaccio marcio senza manico.

Questo era tutto quello a cui Massimo era in grado di pensare, mentre andava verso il commisariato. (66)
¡Diablos! El calor no te deja respirar. Ya verás que por culpa de ese pichafloja de Fusco me voy a pillar la madre de todas las insolaciones, me cago en su puta madre, esa sartén sin mango.

Esto era todo lo que Massimo estaba en condiciones de pensar mientras se dirigía a la comisaría. (67)

Boia de' es una interjección prototípica del vernáculo livornés, una especie de comodín enfático y blasfemo, al tiempo que una expresión sin equivalente inmediato en nuestra lengua. Aja Sánchez (2011) insiste, muy justamente, en el valor pragmático de las interjecciones, mientras que Spitzer (2013 [2007]: 67), por su parte, subrayaba que "danno notizia degli umori di 
chi le pronuncia preannunciando lo stato d'animo del parlante, prima ancora della formulazione del messaggio in quanto tale." Como si tuviera en consideración tales aseveraciones, el traductor ha optado por una expresión que evocara la oralidad y la situación, que fuera idiosincrática, y ha optado por ‘¡Diablos!' Nos encontramos entonces ante una traducción que se sirve de una expresión prototípica del lenguaje oral literario, traducido, como equivalente a otra expresión prototípica del lenguaje oral. Podríamos decir que aquí la traducción no es una mímesis, o una copia, sino una caricatura, caricatura que subraya los rasgos del elemento caracterizado, esto es, la oralidad representada en la escritura.

La cuestión es que a la hora de traducir un discurso hablado escrito pasamos de su representación en la página escrita a su representación oral para poder plasmarlo de nuevo en la página escrita, en un juego de oralidad/escritura casi sin fin. ¿Qué diríamos en nuestra lengua en la situación en la que se encuentra Massimo? ¿Qué representación oral nos haríamos de su parlamento en nuestra lengua? ¿"Diablos"? ¿"Madre mía"? ¿"Atiza?" ¿"Joder"?

Junto a esa interjección (aunque en el original no aparezca signo de admiración alguno) encontramos otra expresión que resulta también bastante singular, tegamaccio marcio senza manico. Para comprobar si se trataba de una invención de Massimo o de una frase hecha en italiano, recurrí a Internet. Aparte de la cita de la novela de Malvaldi, encontré referencia en escasas páginas web (véase por ejemplo Battista en línea), pero con el mismo contenido: la expresión aparece en un texto publicado en Il Vernacoliere, probablemente en el número de julio de 2000 a juzgar por la fecha de publicación de la página que cito, texto (sobre el término uccello) que las páginas web transcriben. Il Vernacoliere es, como se define a sí mismo, un "Mensile di satira, umorismo e mancanza di rispetto in vernacolo livornese e in italiano"; para quien no lo conozca, es una revista semejante a la española El Jueves o a la francesa Charlie Hebdo. De gran difusión en la Toscana, región donde vive Malvaldi, me pregunto si por casualidad nuestro autor no tendría a mano el ejemplar o el recorte del Vernacoliere en su busca de inspiración para el habla de sus personajes.

Según Il Vernacoliere, Catulo llamaba a Lesbia "con gentile metafora 'o sine manubrio putridissima olla' (o tegamaccio marcio senza manico)", por más que, por lo que me consta, en la obra de Catulo no aparezca referencia alguna a ese verso. El Dizionario del lessico erotico (Boggione \& Casalegno 2004: 621), por su parte, me confirma que el término tegame sirve para denominar tanto al órgano sexual masculino como, principalmente, al femenino (ni rastro de Catulo entre las citas recogidas). En cualquier caso, y gracias a 
ese 'me cago en su puta madre' queda patente la (falta de) honorabilidad que para Massimo tiene la madre de Fusco (el comisario), que además de puta es una inútil, una 'sartén sin mango'.

Dentro de la expresividad que caracteriza a este último ejemplo, vemos entonces cómo la técnica de compensación utilizada por el traductor consigue mantener el grado de irritación (y de lenguaje malsonante) de los pensamientos de Massimo. La traducción del lenguaje vulgar y subestándar debe tener presente la fuerza ilocutoria de los enunciados (empezando por ese tegamaccio y terminando por el verbo chiappare, tan castizo, o por el imaginativo affettaminchia) pero también su contexto pragmático y la creatividad lingüística que los caracteriza (Morillas 2012).

\section{Conclusiones}

Hemos visto a lo largo de este trabajo distintos aspectos relacionados con la traducción del habla escrita, en una escala de menor a mayor dificultad traductora, empezando (ejemplo 1) por la función esencial de la sintaxis en la representación del discurso oral, y terminando por la traducción de términos malsonantes (ejemplo 6).

El uso del habla escrita, y en concreto del dialogismo, constituye un recurso fundamental para conferir una determinada inflexión a la obra literaria, y en el caso de La briscola in cinque el tono general se presenta desenfadado, coloquial, e instaura una conversación entre amigos, con voluntad de incluir en el círculo cordial tanto a los tertulianos del BarLume como al público lector de sus aventuras. El humor sirve como elemento cohesionador del relato y de la comunidad público lector/personajes: la expresividad (con la utilización de determinadas locuciones y términos), entendida como elemento generador de empatía (a través de referencias compartidas) serán constantes.

Queda así manifiesta la intención de Malvaldi de establecer contacto directo con quien lee su novela. El dialogismo se presenta como plural, y no se limita al diálogo propiamente dicho: lo constituyen tanto los comentarios de los distintos personajes, que hablan entre sí o incluso para sí, como los del narrador omnisciente. La voluntad principal es la de narrar, y ya sabemos que no existe narración sin destinatario o destinataria, de ahí que también hayamos de hacer referencia a la función apelativa del diálogo.

Está claro, por otra parte, que cuando traducimos la oralidad, y cuando analizamos su traducción, no podemos olvidarnos de que el texto es un conjunto, y como tal debe entenderse, como un todo en el que la técnica de la compensación será un excelente instrumento para buscar el equilibrio entre 
los elementos del texto original que varían al ser traspasados de una lengua a otra. Asimismo, debemos tener presente que de lo que se trata es, insisto, de reproducir el tono de la obra, su dimensión comunicativa y pragmática, y que en el análisis de traducciones la entomología contrastiva constituye una mezquindad.

En las decisiones que se realizan a lo largo de la traducción, por tanto, se tendrá que tener en cuenta, ante un texto como el que nos ha servido de ejemplo:

a) el tipo de relación que se establece entre la obra y el público lector,

b) el tipo de relación que se establece entre los personajes,

c) la caracterización que se realiza de los personajes a través de su forma de hablar (lo que incluye el uso del dialecto),

d) la importancia de dejar definida la parte de la enciclopedia emocional que comparten los protagonistas de la novela, de la cual deben ser partícipes los destinatarios y las destinatarias del texto, y

e) el valor pragmático de las distintas situaciones comunicativas recogidas en la novela.

Por último, debemos aceptar la paradoja de que no podemos pensar en el habla escrita antes de leerla, antes de reconocerla escrita. Además, cuando lo hacemos, cuando el habla escrita es reconocida, se produce una discordancia incómoda: aunque se haya querido escribir lo oral, lo escrito está escrito y es lo que leemos. A esta paradoja se someten tanto el habla escrita como su traducción.

\section{Referencias bibliográficas}

AJA SÁNCHEZ, José Luis. (2011) "La interjección «aho» en las traducciones de los Racconti Romani. Algunas reflexiones sobre las estrategias traslativas de los rasgos lingüísticos regionales en el discurso oral." En: Romana García, M ${ }^{a}$ Luisa; José Manuel Sáenz Rotko \& Pilar Úcar Ventura (coords.) 2011. Traducción e interpretación: estudios, perspectivas y enseñanzas. Madrid: Universidad Pontificia Comillas, pp. 17-36.

ANTONELli, Giuseppe. (2006) Lingua ipermedia. La parola di scrittore oggi in Italia. Lecce: Manni.

BAtTista (2000) "La cultura." Versión electrónica: <http://www.ciao.it/ Tempo_libero_Divertimento_Opinione_44308>

BogGione, Valter \& Giovanni Casalegno. (2004) Dizionario del lessico erotico. Turín: UTET. 
BRANDIMONTI, Giovanni. (2012) "La traducción de las marcas de oralidad: análisis de 'Scusa ma ti chiamo amore' de Federico Moccia y su versión española." En: Elorza, Izaskun; Ovidi Carbonell i Cortés; Reyes Albarrán; Blanca García \& Miriam Pérez-Veneros (eds.) 2012. 'Empiricism and analytical tools for 21 Century applied linguistics.' Selected papers from the 29th International Conference of the Spanish Association of Applied Linguistics (AESLA) held in 2011 in Salamanca. Salamanca: Universidad de Salamanca.

BRUMME, Jenny. (2012) Traducir la voz ficticia. Berlín: De Gruyter.

CADERA, Susanne M. (2011) "Reflexiones sobre la traducción de la oralidad fingida en la narrativa.” En: Romana García, Mª Luisa; José Manuel Sáenz Rotko \& Pilar Úcar Ventura (coords.) 2011. Traducción e interpretación: estudios, perspectivas y enseñanzas. Madrid: Universidad Pontificia Comillas, pp. 37-57.

Chaume, Frederic. (2004) Cine y traducción. Madrid: Cátedra.

FLORES ACUÑA, Estefanía. (2003) "La traducción de los marcadores del discurso en italiano y en español. El caso de insomma." Trans 7, pp. 33-45.

FREUNEK, Sigrid. (2007) Literarische Mündlichkeit und Übersetzung. Am Beispiel deutscher und russischer Erzähltexte. Berlín: Frank \& Timme.

Genette, Gérard. (1996) "Frontières du récit." Comunications 8, pp. 152-163.

GOETSCH, Paul. (1985) "Fingierte Mündlichkeit in der Erzählkunst entwickelter Schriftkulturen." Poetica 17, pp. 202-218.

LÓPEZ SERENA, Araceli. (2007) Oralidad y escrituralidad en la recreación literaria del español coloquial. Madrid: Gredos.

MALVALDI, Marco. (2007) La briscola in cinque. Palermo: Sellerio

Malvaldi, Marco. (2012) La brisca de cinco. Trad. de Juan Carlos Gentile Vitale. Barcelona: Destino

MORILlAS, Esther. (2008) "La traducción como enamoramiento y dependencia: Italia y la literatura estadounidense.” En: Peña, Salvador \& María José Hernández (eds.) 2008. La traducción, factor de cambio. Berna: Peter Lang, pp. 115-130.

MORILLAS, Esther. (2012) "Four letter words and more. Regarding vulgar language and translation." En: García-Izquierdo, Isabel \& Esther Monzó (eds.) 2012. Iberian Studies on Translation E Interpreting. Oxford: Peter Lang, pp. 317-336.

NARBOnA JimÉNEZ, Antonio. (2001) "Diálogo literario y escritura(lidad)." En: Everenz, Rolf (ed.) 2001. Diálogo y oralidad en la narrativa hispánica moderna. Perspectivas literarias y lingüísticas. Madrid: Verbum, pp. 189-208.

NARBOna JimÉnEZ, Antonio. (2009) "Oralidad y escritura, coloquialidad e informalidad." Boletín de la Real Academia Sevillana de Buenas Letras: Minervae Baeticae 37, pp. 111-119.

NenCIONI, Giovanni. (1983) "Parlato-parlato, parlato-scritto, parlato-recitato." En: Nencioni, Giovanni. 1983. Di scritto e di parlato. Discorsi linguistici. Bolonia: Zanichelli, pp. 126-179. 
PAloscia, Fulvio. (2010) "Marco Malvaldi. Quattro amici al bar. E un mistero da risolvere." Versión electrónica: <http://ricerca.repubblica.it/repubblica/archivio/repubblica/2010/06/30/marco-malvaldi-quattro-amici-al-bar-un.html>

RICCI, Laura. (2013) Paraletteratura. Lingua e stile dei generi di consumo. Roma: Carocci.

RodríGuez Medina, Aday. (2005) "La traducción de palabrotas en el lenguaje cinematográfico." En: Cruz García, Laura; Víctor M. González Ruíz; Ana Ma Monterde Rey \& Guillermo R. Navarro Motesdeoca (eds.) 2005. Traducir e interpretar: visiones, obsesiones y propuestas. Las Palmas de Gran Canaria: Servicio de Publicaciones, pp. 269-281.

Rojo López, Ana María \& Javier Valenzuela Manzanares. (2000) "Sobre la traducción de las palabras tabú." Revista de Investigación Lingüística 3:1, pp. 207-220.

RosA, Alexandra Assis. (2015) "Translating orality, recreating otherness." Translation Studies 8:2, pp. 1-17.

SAN ViCEnTE, Félix \& Esther Morillas (eds.) (2014) Cuadernos AISPI 4 (Número dedicado a "Oralidad contrastiva español-italiano: aspectos gramaticales, discursivos y textuales").

Soler PARdo, Betlem. (2013) "Translating and Dubbing Verbal Violence in Reservoir Dogs. Censorship in the Linguistic Transference of Quentin Tarantino's (Swear) Words." Jostrans 20 (Número especial: Translating Multimodalities, edited by Carol O'Sullivan y Caterina Jeffcote eds.), pp. 122-133.

SPITZER, Leo. (2013 [2007]) La lingua italiana del dialogo. Caffi, Claudia \& Cesare Segre (eds.). Trad. de Livia Tonelli. Milán: Il Saggiatore.

TURI, Nicola. (2011) Declinazioni del canone americano in Italia tra gli anni quaranta e sessanta. Roma: Bulzoni. 


\section{NOTA BIOGRÁFICA / BIONOTE}

Esther Morillas es Profesora Titular de Traducción Italiano/Español en la Universidad de Málaga. Sus publicaciones están centradas en la traducción literaria, la recepción de la literatura italiana en España, la variación lingüística, la estilística de la traducción y las relaciones entre arte y escritura. Pertenece a los grupos de investigación "Traductología y Traducción" y "Lectura de la historia del arte contemporáneo desde la perspectiva de género" y ha sido profesora visitante en las Universidades de Trieste, La Sapienza (Roma), Bolonia, Cambridge (Reino Unido) y Pisa. Ha sido secretaria (2003-2008) y directora (2008-2014) de TRANS. Revista de traductología. Ha traducido a autores como Umberto Saba, Attilio Bertolucci, Giovanni Pascoli, Franco Loi, Sandro Veronesi o Alessandro Mari.

ESTHER MORILLAS is an Assistant Professor of Translation Italian/Spanish at the University of Málaga. Her publications are focused on literary translation, the reception of Italian literature in Spain, translation's stylistics and relationship between art and writing. Visiting professor in different European universities, Esther Morillas is a member of the Research Groups "Traductología e interculturalidad", centred on traductology and cross-cultural studies, and "Lectura de la historia del arte contemporáneo desde la perspectiva de género", focused on contemporary art and gender. She has also been the editor of the journal TRANS. Revista de Traductología from 2008 to 2014. She has translated authors such as Umberto Saba, Attilio Bertolucci, Giovanni Pascoli, Franco Loi, Sandro Veronesi or Alessandro Mari. 
